\title{
The Cost of Injustice
}

Written by: Will Friend, OECD Observer

Last update: 2 March 2020

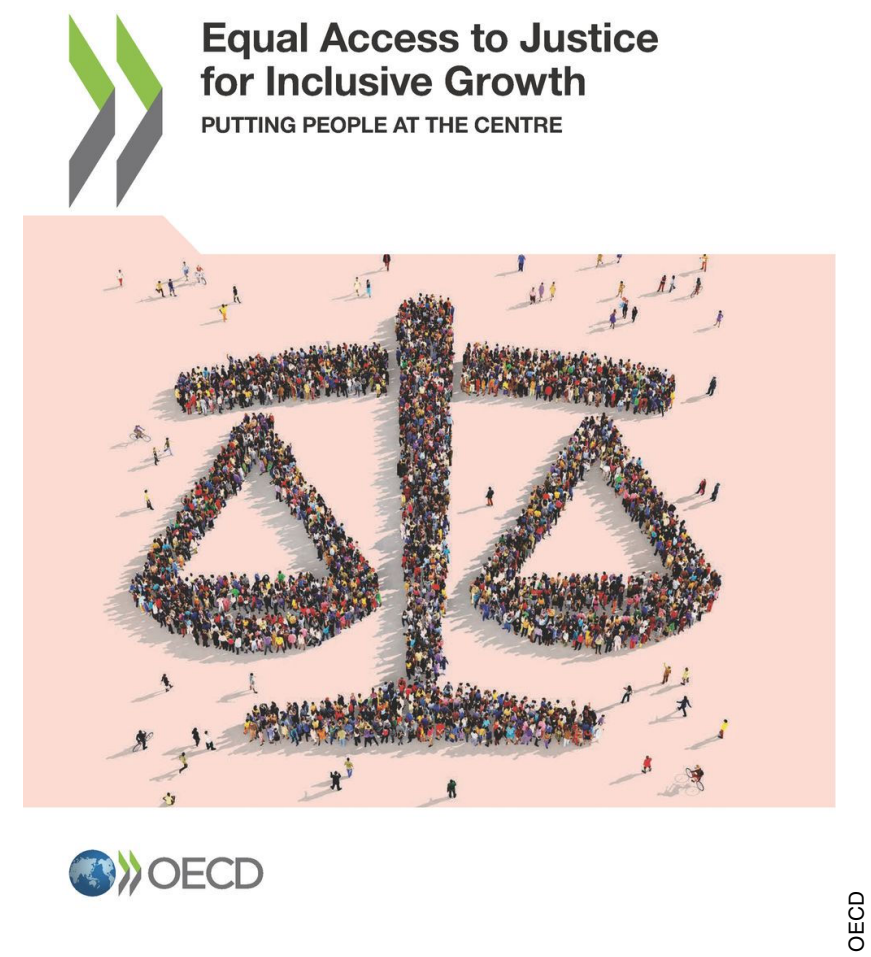

$£ 3.5$ billion. That's the amount of money-nearly US $\$ 4.5$ billionthe UK economy is estimated to lose every year due to unresolved legal issues and ongoing disputes. Providing equal and efficient access to legal services - like mediation or legal representation-is considered to be a core duty of democratic justice systems. As Equal Access to Justice for Inclusive Growth shows, this equal provision of justice services is not only a good in itself, but is also essential for promoting inclusive economic growth.

Wealth, gender, race, disability, and education: all these factors influence how citizens access legal services. The report notes that "unequal access to and discrimination in sectors such as" health, employment, education and housing "create real barriers to economic participation". People suffering from discrimination require legal remedies and support to help them continue to 
participate in economic and community life. Yet it is these same vulnerable individuals who face the most hurdles in accessing legal services-and this unequal access has tangible economic and social costs. For example, a Wisconsin study estimated that victims of domestic violence incur costs of US\$3,400 for the likes of medical care and psychological counselling. Domestic violence is another area in which obtaining legal services needs to be made easier.

Fortunately, local and national governments are beginning to improve the "people-centred" nature of legal and justice services and to enhance equal access to legal services. By targeting and designing legal services to assist those who previously had difficulties accessing them, governments are not only helping their citizens but also saving money. One study in California found that the state saved US $\$ 7.70$ for every dollar spent on providing legal services by eliminating excess legal hearings. A 2009 study found that tenants in the US who received full legal representation were significantly more likely to stay in their homes (55\%) than those with limited or no representation (18\% and 14\% respectively). Ensuring that citizens avoid eviction is not only intrinsically good, but also saves governments the economic and social costs of homelessness.

OECD (2018), Equal Access to Justice for Inclusive Growth: Putting People at the Centre, OECD Publishing, Paris. https://doi.org/10.1787/597f5b7f-en 